\title{
O ENSINO DO EMPREENDEDORISMO NOS CURSOS DE PÓS-GRADUAÇÃO EM ADMINISTRAÇÃO NO BRASIL ${ }^{1}$ \\ 2
}

\section{THE EDUCATION OF THE ENTREPRENEURS' IN THE COURSES OF PÓS- GRADUATION IN MANAGEMENT IN BRAZIL}

\author{
Danusa Cunha Flores ${ }^{3}$ \\ Marianne Hoeltgebaum ${ }^{4}$ \\ Amelia Silveira $^{5}$
}

\begin{abstract}
RESUMO: O empreendedorismo tem tido um valor crescente no mundo em virtude das inúmeras mudanças que vêm ocorrendo, principalmente, nas relações de trabalho e na questão de emprego e renda. A formação de empreendedores tornou-se questão importante. Os objetivos buscaram caracterizar os programas de pós-graduação em administração, no Brasil, que possuem linhas de pesquisa, área de concentração e disciplinas de empreendedorismo em sua estrutura curricular. Foram analisados os planos de ensino das disciplinas de empreendedorismo quanto às ementas, cargas-horárias e bibliografias. A pesquisa foi exploratória, com método qualitativo. A população foi constituída por 16 programas de mestrado e doutorado reconhecidos pela Coordenação de Aperfeiçoamento de Pessoal de Nível Superior (CAPES). Os resultados revelam que o número de disciplinas de empreendedorismo e a carga horária apresentaram uma tendência no crescimento da ênfase do empreendedorismo nos programas analisados. O plano de negócios, inovação, criação de novos negócios e reconhecimento de oportunidades foram os tópicos mais abordados. Filion, Birley e Muzyca, e Drucker foram os autores mais presentes nas bibliografias das disciplinas. A conclusão evidenciou que o tema do empreendedorismo vem se projetando neste nível de estudos de pós-graduação em administração, sendo relevante o papel das Instituições de Ensino Superior (IES).
\end{abstract}

PALAVRAS-CHAVE: Formação de empreendedores. Programas de pós-graduação em administração. Instituições de Ensino Superior (IES). Brasil.

ABSTRACT: The entrepreneurs' formation has been growing in term of value in the world because of the important changes affecting mainly the labor relationship, employment and income. The entrepreneurs' formation becomes an important subject. The aim of the present paper is to characterize the post-graduate programs in Business Administration, in Brazil, that have research lines, specific concentration area in entrepreneurship and offer disciplines in his curriculum structure regarding this issue. The teaching plans of the entrepreneurship disciplines were analyzed as for the menus, load-

\footnotetext{
${ }^{1}$ Artigo publicado no EnEPQ - I Encontro de Ensino e Pesquisa em Administração e Contabilidade - Recife / PE 21 a 23 de novembro de 2007.

Artigo Recebido em 11.11.2008. Revisado por pares em 11.11.2008. Recomendado em 11.11.2008 por Denise Del Pra Netto Machado (editora). Publicado em 15.12.2008.

Organização Responsável pelo periódico: Universidade regional de Blumenau - FURB - www.furb.br/rn

${ }^{2}$ O Presenta artigo teve alteração na ordem dos autores em 10 de Março de 2010, com a justificativa de manter a mesma sequencia original do artigo publicado no evento EnEPQ 2008.

${ }^{3}$ Mestre em Administração pelo Programa de Pós-Graduação em Administração - danusaflores@hotmail.com

${ }^{4}$ Professora do Programa de Pós-Graduação em Administração e do Programa de Pós Graduação em Ciências Contábeis da Universidade Regional de Blumenau - marianne@furb.br

${ }^{5}$ Professora do Programa de Pós-Graduação em Administração e do Programa de Pós Graduação em Ciências Contábeis da Universidade Regional de Blumenau - Doutora em Ciências da Comunicação - Universidade de São Paulo, USP, Brasil - amelia@furb.br
} 

BRASIL

hourly and bibliographies. The research was exploratory, using a qualitative method. The population was constituted by the 16 programs for masters and doctorates degree recognized by the Coordination of Personal Improvement of Superior Level (CAPES). The results show that the menus and load- hours have a tendency to focus on the growth of entrepreneurship in the programs analyzed. The business plan, innovation, creating new business opportunities and recognition were the most discussed topics. Filion, Birley and Muzyca, and Drucker were the authors; they have been mentioned as references in the most bibliographies of offered disciplines. The conclusion evidenced that the theme of entrepreneurship is winning field in this level of studies in the Brazilian post-graduate in administration, being relevant to the role of Higher Education Institutions (HEI)

KEYWORDS: Entrepreneurs' formation. Post-graduate programs for master and doctorates degree in administration. Higher Education Institutions (HEI). Brazil. 


\section{INTRODUÇÃO}

O empreendedorismo é, nestas últimas duas décadas, principalmente em países em desenvolvimento, como o Brasil, uma tendência mundial, decorrente das relações entre empregado e empregador no mundo do trabalho, e da escassez de empregos formais. Conforme Schumpeter (1984), os empreendedores assumem papel relevante no desenvolvimento econômico e social desses países. Esta contribuição dos empreendedores, associada à geração de novos negócios, de produção produtos e serviços inovadores "é um impulso fundamental que aciona e mantém em marcha o motor capitalista, que retroalimenta, sistemática e continuamente, a estrutura econômica do país, em detrimento da estrutura mais antiga.” (SCHUMPETER, 1984, p. 103-104). Assim, um dos pilares do desenvolvimento econômico, segundo o Global Entrepreneurship Monitor (GEM), é a existência de indivíduos dispostos aos riscos de empreender e viabilizar seu próprio negócio. "Captar, descrever e analisar o fenômeno do empreendedorismo é, portanto, fundamental para o desenho de ações de promoção do progresso e do bem-estar." (GEM, 2006). Tomando ainda como base estes números que revelam a posição brasileira quanto ao empreendedorismo (GEM, 2006), e mesmo sabendo-se que uma grande proporção do crescimento econômico em países em desenvolvimento pode ser atribuída à criação de novos negócios, realizados por empreendedores independentes e recém graduados, considera-se importante a inclusão de disciplinas de empreendedorismo nas instituições de ensino. Entende-se que estas poderão auxiliar para que o empreendedor do futuro amplie e agregue conhecimentos para aumentar sua capacidade de gerir e manter seu próprio negócio.

Tratando-se do ensino superior, uma das tarefas das instituições de ensino superior (IES) é concretizar as aspirações do profissional do futuro, em relação às expectativas do mercado de trabalho. No caso específico do ensino de empreendedorismo em programas de pós-graduação em Administração, disciplinas devem oportunizar conhecimentos que ampliem a formação superior básica. Devem, ainda, estar em sintonia com as demandas da sociedade, assim como com a geração de conhecimentos na área de empreendedorismo, por meio de pesquisa científica. Desta forma, poderá haver contribuição mais efetiva para a qualidade de vida das pessoas, minimizando as desigualdades sociais, e oportunizando a geração de empregos e de renda. Neste contexto, a educação superior, no nível de pós-graduação, apresenta-se como uma alternativa auxiliar de desenvolvimento de inovações e de oportunidades de trabalho, atendendo às necessidades do mercado, dos cidadãos e da sociedade e monitorando da melhoria da capacidade de trabalho.

Della Giustina (2005) destaca que há relevância na formação de empreendedores, mas alerta que isto é um grande desafio, sobretudo nos cursos de graduação e pós-graduação:

O desenvolvimento do perfil empreendedor, com base no aprender a aprender, incide, em grande parte, do abrir espaço para a criatividade. No entanto, buscar referenciais para apreender as competências, detectar os melhores conteúdos programáticos, captar a dinâmica educacional mais adequada e descobrir mecanismos de ação que coloquem em ação a atividade pedagógica desejada representa hoje o grande desafio para a concepção do empreendedor nos cursos de graduação e pós-graduação. (DELLA GIUSTINA, 2005, p. 34).

É exatamente nesse ponto, que se defende a necessidade de disponibilizar disciplinas que se volte para a formação de empreendedores em programas de pós-graduação de 
Administração, no Brasil. Hoje, ser empreendedor é quase um imperativo, significando dizer que visão de futuro e talento individual é elemento propulsor das novas idéias. No entanto, para o sucesso de empreendimentos inovadores, é preciso análise, planejamento estratégicooperacional e capacidade de desenvolvimento, tanto fora da organização, quando se inicia um novo empreendimento, quanto dentro da organização, quando o funcionário começa a ter visão de dono do negócio. É necessário, ainda, que os empreendedores se convertam em multiplicadores de conhecimento, tendo como objeto a criação de empresas e de novos postos de trabalho. Conseqüentemente, geradores de maior riqueza interna e melhoria da qualidade de vida das pessoas, principalmente no mercado atual onde a competição está cada vez mais acirrada, os consumidores cada vez mais exigentes e o emprego cada vez mais escasso.

Assim, torna-se relevante realizar um levantamento para identificar os enfoques de empreendedorismo adotados nos programas de pós-graduação em Administração no Brasil. Neste ponto, cabe questionar: Até que ponto os programas de pós-graduação em Administração, no Brasil, voltam-se para o enfoque do empreendedorismo como linha de pesquisa e área de concentração, e oferecem disciplinas de empreendedorismo em sua estrutura curricular?

Considerando-se o desconhecimento destes aspectos, uma vez que esse tema é emergente e cada IES tem autonomia para definir linha de pesquisa, área de concentração e disciplinas que melhor expressem os objetivos do programa, este estudo pretende aumentar o conhecimento sobre o assunto. Pretende, ainda, servir de base para os próprios programas de pós-graduação em Administração. Para os que adotam linha de pesquisa e área de concentração, e incluem disciplinas de empreendedorismo em seus currículos, e que poderiam desenvolver estudos comparativos e de avaliação, a partir dos resultados revelados neste trabalho, como para os que não incluem.

Como este entendimento, os objetivos da pesquisa voltaram-se, inicialmente, para a identificação dos programas de pós-graduação em administração, no Brasil, que possuem linhas de pesquisa, área de concentração e/ou disciplinas de empreendedorismo em sua estrutura curricular. A seguir, foram analisados os planos de ensino das disciplinas de empreendedorismo quanto às ementas e às cargas-horárias. Também foi realizada a analise da bibliografia recomendada nestes planos de ensino. Nesta parte, foi considerado o nome dos autores, o título e o subtítulo da obra, o tipo de fonte bibliográfica, e a data de publicação dos documentos relacionados nestas bibliografias constantes nos planos de ensino das disciplinas de empreendedorismo, em cada um dos programas pesquisados.

\section{ENSINO DE EMPREENDEDORISMO: EVOLUÇÃO E FOCO NO BRASIL}

Em vários países já se percebe a presença do empreendedorismo nos currículos escolares, o que reflete a visão de que a educação é passo primordial para o desenvolvimento dos futuros empreendedores. Pardini e Paim (2001) afirmam que o ensino da arte de empreender, em universidades, é relativamente recente. Traçam um panorama mundial, afirmando que em 1947 a Harvard Business School criou o primeiro curso sobre gerenciamento de pequenas empresas. Dolabela, (1999) afirmou que houve crescimento no ensino de empreendedorismo nas IES nos últimos 30 anos. Só nos Estados Unidos, o número de universidades que oferecem cursos na área subiu de dez, em 1967, para 1064, em 1998. O trabalho de Menzies (1998) repertoriou as "Strategies and Best Practices of Entrepreneurship 
Centres in Canada”, apresentado um levantamento dos Centros de Empreendedorismo existentes.

Segundo Bernardes e Martinelli (2003),

\begin{abstract}
Com o crescimento do interesse a respeito das práticas empreendedoras e da criação de empresas, a pesquisa e o estudo do empreendedorismo e das PME (Pequenas e Médias Empresas) vem se desenvolvendo enormemente. Muitos Programas específicos e/ou Centros de Empreendedorismo ligados a instituições de ensino superior são criados, sendo crescente o número de experiências reportadas, que visam a propagar as práticas e compartilhar os resultados que aumentem a compreensão dos riscos e facilidades dos que pretendem trabalhar nesta via. (BERNARDES e MARTINELLI, 2003, p. 1)
\end{abstract}

Bernardes e Martinelli (2003) realizaram visitas exploratórias, em 2002, em seis centros de empreendedorismo, sendo, três no Canadá, na província do Quebec, e três na região de Boston, nos Estados Unidos. Mostraram o que estava sendo realizado nos dois países quanto ao empreendedorismo.

Guimarães (2002) estudou o modelo de formação empreendedora na graduação da Babson College, localizado em Wellesley, Machassuchets, afirmando que esta instituição tem uma organização didático-pedagógica que possibilita o esclarecimento acerca dos limites, dificuldades e barreiras à entrada e permanência nos negócios.

Klapper (2004) estudou 200 estabelecimentos de ensino superior que se interessam pelo empreendedorismo na França. Porém, se comparado com o Canadá e os Estados Unidos, o ensino de empreendedorismo na França está emergindo.

Segundo Matlay (2005), no contexto de "cultura do empreendedorismo” os sucessivos governos do Reino Unido em esforços combinados buscaram facilitar o desenvolvimento de diplomados universitários para aumentar o número de empresários altamente qualificados. Segundo este autor, entretanto,

No Reino Unido, há escassez de pesquisa conclusiva e empiricamente rigorosa para unir ensino de empreendedorismo e o currículo pertinente para um significante aumento sustentável de graduados com disposição para empreender. A literatura internacional neste tópico sofre de várias faltas e é duvidoso que o EUA, o Canadá, a Austrália ou experiência da Nova Zelândia provariam mais útil que a literatura européia neste tópico. (MATLAY, 2005, p. 11)

Na Irlanda do Norte os debates teóricos e pedagógicos dentro da academia sobre empreendedorismo têm sido contínuos, assim como o questionamento de como o empreendedorismo pode ser ensinado. (JONES-EVANS; WILLIAMS; DEACON, 2000). Garavan, Fleming e Cinneide (1997), afirmam ser notável que o ensino do empreendedorismo ensinado em universidades e faculdades irlandesas encoraje seus graduandos a olhar de forma mais criativa às oportunidades, resultando em níveis mais altos de atividade empresarial entre os irlandeses. Na Ásia, o ensino do empreendedorismo, segundo a revisão de literatura, está em seus primeiros estágios, sendo exemplo a China, que embora reconheça a necessidade e a importância do empreendedorismo, ainda mantém cursos e iniciativas isoladas, não incorporadas às ementas e planos de ensino das escolas e universidades.

Li, Zhang e Matlay (2003), fazendo uma retrospectiva de como começou o ensino do empreendedorismo na China, observam que o desenvolvimento do ensino superior, neste país, 
foi influenciado pelas políticas radicais que prevaleceram durante os anos sessenta, com desdobramentos até o presente.

A África tem passado por dificuldades históricas de empregabilidade. O ensino do empreendedorismo ainda é muito incipiente nas instituições de ensino, e está em fase inicial de implantação, sendo que várias iniciativas começam a surgir por força da necessidade. (NORTH, 2002). Co e Mitchell (2006) avaliaram o nível de desenvolvimento do ensino do empreendedorismo, a fim de determinar sua importância nas IES africanas. Os resultados indicaram que o ensino do empreendedorismo na África do Sul está numa fase de desenvolvimento, em suas fases iniciais, embora algumas das IES estejam envolvidas com o assunto desde os anos 90.

No Brasil, de acordo com Filion (2000), apesar das grandes dificuldades de se desenvolver o empreendedorismo, o movimento para o ensino dessa disciplina, iniciado há alguns anos, é um passo a caminho da criação de uma cultura empreendedora que dará suporte ao processo de desenvolvimento econômico.

Ramos e Ferreira (2004), em pesquisa comparativa sobre as práticas de três IES americanas e 21 brasileiras, concluíram que o empreendedorismo, como campo de conhecimento, ainda apresenta-se em fase de construção de seus pressupostos, sendo necessários estudos empíricos que legitimem e validem seus conceitos.

Na pesquisa de Della Giustina (2005), realizada nos programas de pós-graduação em Administração, da região sul do Brasil, quanto ao tema do empreendedorismo, há toda uma análise dos programas em si, quanto às suas características, bem como da produção científica gerada no período entre 1972 e 2005 , na temática do empreendedorismo.

Henrique e Cunha (2006) realizaram um estudo sobre o estado da arte das metodologias e práticas didático-pedagógicas utilizados no ensino de empreendedorismo nos cursos de graduação e pós-graduação nacionais e estrangeiros. Inicialmente, os autores desenvolveram um histórico do ensino de empreendedorismo nas IES e sua importância no desenvolvimento sócio-econômico dos países e na geração de inovações. Os principais resultados indicam que as IES estão implantando o ensino de empreendedorismo em suas grades curriculares em sinergia com as metodologias e práticas didático-pedagógicas mais eficazes para seu aprendizado, mas sem deixar de lado, em muitas ocasiões, os métodos tradicionais de ensino. Henrique e Cunha (2006) salientam que, por se tratar de uma pesquisa que analisa publicações em vários países, nota-se certa variedade nas práticas e metodologias utilizadas. Entretanto, há clara preferência por práticas pedagógicas que incitem a ação do aluno - como plano de negócios, simulação de negócios, jogos, desenvolvimento de empresas ou produtos virtuais ou reais, visitas a empresas e empreendedores e estudos de caso.

Flores (2006), ao analisar o ensino do empreendedorismo nos programas de pósgraduação brasileiros revisou a literatura internacional e nacional sobre o tema. Mais detalhadamente, apresenta os trabalhos em eventos da área de Administração. No período de 2001 a 2006, entre outros, mostra os doze trabalhos do Encontro de Estudos sobre Empreendedorismo e Gestão de Pequenas Empresas (EGEPE). No Encontro Nacional realizado pela Associação Nacional de Pós-Graduação e Pesquisa em Administração (EnANPAD), analisa as nove pesquisas. No Encontro Nacional dos Cursos de Graduação em Administração (ENANGRAD) revê os dez estudos apresentados. Há, portanto, um interesse pelo estudo do ensino do empreendedorismo que permeia os trabalhos apresentados nos principais eventos nacionais da área de administração. 


\section{MÉTODO E TÉCNICAS DE PESQUISA}

A pesquisa foi exploratória e o método qualitativo. O delineamento foi bibliográfico e documental. A população foi definida de forma intencional, não-probabilística, de conveniência, considerando os objetivos do estudo. Assim, foram considerados todos os programas stricto sensu brasileiros de Administração, de mestrado e de doutorado, homologados pelo Conselho Nacional de Educação (CNE) e reconhecidos pela Coordenação de Aperfeiçoamento de Pessoal de Nível Superior (CAPES), e que possuem linha de pesquisa, área de concentração e disciplinas de Empreendedorismo. O estudo foi censitário. O corte de tempo foi transversal, ou seja, no momento presente da coleta de dados, de outubro a dezembro de 2006.

As 16 IES definidas foram: Fundação Universidade do Ceará - FUNECE-CE, Universidade Federal de Minas Gerais - UFMG-MG, Universidade Federal de Uberlândia UFU-MG, Pontifícia Universidade Católica de Minas Gerais - PUC-MG, Faculdades Integradas de Pedro Leopoldo - FPL-MG, Pontifícia Universidade Católica do Paraná - PUCPR, Centro Universitário Positivo - UNICENP-PR, Universidade Federal do Rio de Janeiro UFRJ-RJ, Faculdade de Economia e Finanças - IBMEC-RJ, Universidade Regional de Blumenau - FURB-SC, Universidade de São Paulo USP-SP, Universidade Estadual de Londrina - UEL e a Universidade Estadual de Maringá - UEM (que fizeram uma parceria a fim de oferecer o programa de mestrado em Administração - e contaram uma só vez), Universidade Estácio de Sá - UNESA-RJ, Universidade Católica de Santos - UNISANTOSSP, Universidade Federal Rural do Rio de Janeiro - UFRRJ-RJ, e Fundação Getúlio Vargas FGV-SP.

Para coleta dos dados houve acesso ao sitio da Capes (CAPES, 2006). Houve ainda acesso aos sítios das 16 IES, além de comunicação com as Secretarias destes programas, por meio de correio eletrônico e telefone, solicitando as informações necessárias. Os dados foram analisados por meio de análise documental, de conteúdo e de contagem simples de freqüência.

\section{RESULTADOS DA PESQUISA}

De forma geral, entre outros resultados, destacam-se o que segue. A análise das áreas de concentração, segundo dados coletados do sítio das IES, permite verificar que Gestão das Organizações aparece em nove programas (18,38\%), e os itens Estratégia, Finanças e Mercadologia em quatro programas (8,16\%). Empreendedorismo, Recursos Humanos e Administração Geral, aparecem em três programas (6,12\%). E com duas indicações, cada uma, aparecem os itens Internacionalização, Operações, Sistemas de Informações e Gestão de Negócios (4,08\%). Outros itens com apenas uma indicação, com onze indicações, perfazem $22,46 \%$.

As linhas de pesquisa colocam o empreendedorismo em terceiro lugar na ordem de temática, sendo precedido por estratégia e gestão das organizações. A análise das linhas de pesquisa, segundo dados coletados do sítio das IES, mostra que Estratégia aparece como área de concentração em onze programas (14,67\%), Gestão das Organizações em oito (10,67\%), e Empreendedorismo em seis programas (8,00\%). Os itens Mercadologia e Finanças constam em cinco programas (6,67\%) e Gestão da Cadeia de Suprimentos e Sistemas de Informação, aparecem em quatro programas (5,33\%). Outros itens com menos de três indicações totalizam 32 indicações (42,66\%). O empreendedorismo, como área de concentração do curso, figura em 
três dos programas estudados. Assim, os programas estão mais voltados para gestão das organizações, estratégia, finanças e marketing.

Quanto às ementas, segundo dados do site das IES, pode-se verificar que Plano de Negócios obteve oito indicações (10,96\%), o item inovação sete indicações (9,59\%). Os itens Criação de Novos Negócios e Reconhecimento de Oportunidades tiveram seis indicações (8,22\%). Processo Empreendedor e Perfil Empreendedor obtiveram cinco indicações cada um (6,85\%). Outros itens, com menos de quatro indicações, somaram 36 indicações (49,31\%).

Ao analisar o número e a carga horária das disciplinas de empreendedorismo constatouse que houve um aumento no numero de disciplinas, ao longo do tempo. Em 2004, havia 18 disciplinas. Em 2007, existem 23 disciplinas nos programas. Cresceu de 708 para 849 o número de horas-aula. Houve, portanto, tendência favorável à inserção de disciplinas de empreendedorismo nos programas estudados. As disciplinas de empreendedorismo apresentam como assuntos mais abordados, o que segue: o empreendedorismo, o empreendedor, a gestão de negócios na pequena empresa, e as pessoas que nela atuam. Em três programas a disciplina é obrigatória. São eles: FURB/SC, FGV/SP e FPL/MG. É eletiva nos demais programas estudados. A distribuição da carga horária das disciplinas de empreendedorismo, o nome das disciplinas, o sítio de onde foram coletadas, o nome da IES onde o programa de pós-graduação está inserido, e a unidade federativa brasileira, constam no quadro 1.

\begin{tabular}{ccccc} 
CH & NOME DAS DISCIPLINAS & SITE & IES & UF \\
\hline- & Ensino e Pesquisa em Administração para Pequenos e Médios & - & FUNECE & CE \\
& Negócios & & & \\
\hline 30 & Empreendedorismo e Plano de Negócios & Capes & UFMG & MG \\
30 & Empreendedorismo em Finanças & IES & & \\
\hline 60 & Empreendedorismo em Finanças & Capes & UFU & MG \\
60 & Empreendedorismo & IES & & \\
\hline 30 & Criação de Empreendimentos de Base Tecnológica & Capes & PUC/MG & MG \\
45 & Inovação e Empreendedorismo & IES & & \\
\hline 30 & Inovação e Empreendedorismo & Capes & FPL & MG \\
\hline 30 & Empreendedorismo e Gestão de Negócios & IES & & \\
\hline 30 & Empreendedorismo e Gestão de Negócios & Capes & & \\
\hline 30 & Seminário Avançado em Gestão da Inovação & IES & & \\
\hline 30 & Pesquisa em Empreendedorismo & PUC/PR & PR \\
30 & Empreendedorismo e Inovação & & \\
\hline 45 & Empreendedorismo e Inovação & IES & UNICENP & PR \\
\hline 45 & Empreendedorismo e Organizações Empreendedoras & IES & & \\
\hline 45 & Comportamento e Competências do Empreendedor & Capes & UFRJ & RJ \\
\hline 40 & Empreendedorismo & IES & & \\
\hline 30 & Empreendedorismo & Capes & & \\
\hline 20 & Perfil e Processo Empreendedor & IES & & \\
\hline 45 & Perfil e Processo Empreendedor & Capes & IBMEC & RJ \\
\hline 45 & Empreendedorismo & IES & & \\
\hline 45 & Empreendedorismo & Capes & & \\
\hline 45 & Projeto de Novos Negócios & Capes & FURB & SC \\
\hline 45 & Empreendedorismo e Início de Novos Negócios & & \\
\hline 45 & Empreendedorismo & & \\
\hline 45 & Inovac̃o e Empreendedorismo & & \\
\hline
\end{tabular}

Revista de Negócios, ISSN 1980-4431, Blumenau, v13, n. 2, p. 93 - 104, Abril/Junho 2008. 


\begin{tabular}{|c|c|c|c|c|}
\hline 30 & Plano de Negócios - TEA & Capes & & \\
\hline 45 & Empreendedorismo Corporativo & IES & & \\
\hline 45 & Empreendedorismo Social & IES & & \\
\hline 45 & Formação de Novos Empreendimentos & IES & & \\
\hline 48 & Criação de Empresas e Empreendimento de Base Tecnológica & Capes & USP & SP \\
\hline 60 & Criação de Empresas e Empreendimento de Base Tecnológica & IES & & \\
\hline 45 & Empreendedorismo & Capes & UEM/UEL & PR \\
\hline 45 & Empreendedorismo e Gestão de Pequenas e Médias Empresas & IES & & \\
\hline 45 & Pesquisa em Empreendedorismo & IES & & \\
\hline 45 & Capacitação Empreendedora & Capes & UNESA & RJ \\
\hline NÃO & Não possui mais a disciplina de empreendedorismo nem afins & IES & & \\
\hline 45 & Gestão de Pessoas e Empreendedorismo & Capes & UNISANTOS & SP \\
\hline 45 & Gestão de Pessoas e Empreendedorismo & IES & & \\
\hline 30 & Empreendedorismo & Capes & UFRRJ & $\mathrm{RJ}$ \\
\hline 30 & Empreendedorismo e Negócios & IES & & \\
\hline 12 & Gestão de Novos Negócios I & IES & FGV & SP \\
\hline 12 & Gestão de Novos Negócios II & IES & & \\
\hline
\end{tabular}

Quadro 1 - Distribuição das disciplinas dos programas de pós-graduação em Administração, segundo sítios da CAPES e das IES, outubro de 2006.

Fonte: Dados da pesquisa.

A análise das bibliografias constantes nos planos de ensino das disciplinas de empreendedorismo estudados nota-se que os autores que são relacionados em maior numero são Filion, Birley e Muzyca, e Drucker, sendo a quase totalidade formada por livros, da decada de 90 e, alguns mais atuais, de 2002 a 2007.

Della Giustina (2005) encontrou dois autores como os mais citados nas bibliografias recomendadas nos planos de ensino dos programas de pós-graduação em Administração da região sul do Brasil: Dolabela e Reynolds. Esta autora encontrou ainda, acerca da produção científica nos programas de pós-graduação em Administração, na região sul do Brasil, ser o empreendedorismo um tema atual, mas ainda pouco abordado em pesquisas nos referidos programas. As 39 dissertações estudadas, que apresentavam as palavras empreendedorismo e/ou empreendedor no título, não tinham como citação um grupo de autores fortemente citados. Louis Jacques Filion foi o autor mais indicado pelos mestrandos que abordaram 0 empreendedorismo em suas dissertações. (DELLA GIUSTINA, 2005)

\section{CONCLUSÃO}

Em todas as economias modernas a atividade empreendedora é uma prioridade política. Novos negócios são fontes de inovação e de idéias, criando riqueza e emprego, e aumentando a competição. Permite que pessoas de todas as classes, não só os graduados, consigam colocar em prática seu potencial. A Organisation for Economic Cooperation and Development (OECD) e o Global Entrepreneurship Monitor (GEM) mostram uma correlação direta entre atividade empreendera e o desenvolvimento econômico. (HEGARTY, 2006)

Quanto ao envolvimento das IES como formadora de empreendedores, entende-se que tudo leva a crer que, em países onde o ensino do empreendedorismo é mais evidente, como nos Estados Unidos e Canadá, também é maior a atividade empreendedora. Esta relação, no entanto, merece estudo específico, não tendo sido objeto do presente trabalho. 
As áreas de concentração estão mais voltadas para gestão das organizações, estratégia, finanças e marketing. O empreendedorismo tem 6,12\% das indicações como área de concentração, com uma diferença de 12,26 pontos percentuais para o primeiro colocado: gestão das organizações. Quanto às linhas de pesquisa nos programas de pós-graduação em Administração, no Brasil, o empreendedorismo figura em terceiro lugar, precedido de estratégia e de gestão das organizações.

O número de disciplinas de empreendedorismo e a carga horária apresentaram aumento de 27,80\%, crescendo de 18 para 23 disciplinas, e reafirmando uma tendência no crescimento da ênfase do empreendedorismo nos programas analisados. O plano de negócios, inovação, criação de novos negócios e reconhecimento de oportunidades foram os tópicos mais abordados. Quanto à obrigatoriedade da disciplina de empreendedorismo nos programas participantes deste estudo, somente em três programas a disciplina de empreendedorismo é obrigatória, nos outros programas a disciplina é eletiva, ou seja, o aluno pode optar em cursá-la ou não. Nota-se também, que a FURB é o único programa que além da linha de pesquisa em empreendedorismo, mantém a disciplina de empreendedorismo como obrigatória. Os programas da UFMG, UNICENP, UFRJ, e UEM/UEL, embora tenham como linha de pesquisa o empreendedorismo, as disciplinas referentes ao assunto são eletivas, e não obrigatórias.

Os autores mais citados no ementário das disciplinas, com cinco indicações foram: Filion, Birley e Muzyca, e Drucker.

$\mathrm{Na}$ análise do referencial bibliográfico, 46,9 \% das referências recomendadas nos programas de ensino estudados estavam em língua estrangeira, e 53,45 \% em língua portuguesa. Este resultado contraria, em parte, o que se pressupõe quanto às citações em trabalhos acadêmicos, onde a literatura internacional deveria prevalecer.

De maneira geral, pode-se concluir que o tema do empreendedorismo vem ganhando terreno no nível de estudos de pós-graduação stricto sensu, ao longo do tempo, no Brasil, e que as IES desempenham papel relevante neste contexto. Estudos constantes na literatura vêm, de forma cada vez mais sistemática, reafirmar a importância e a necessidade de estudos ligados à área do empreendedorismo nos programas de pós-graduação em Administração das IES brasileiras. Nestes estudos percebe-se a visão de que os programas de pós-graduação foram vistos como formadores de mestres e doutores, disseminadores do conhecimento empreendedor, e de gerentes qualificados que poderão melhor se desempenhar no competitivo mercado de trabalho.

Os programas de pós-graduação em Administração, no Brasil, de forma mais específica, devem aproximar o ensino superior da realidade do mercado, formando e educando pessoas autônomas e criativas ajustadas à nova ordem econômica, servindo tanto para aqueles que têm seu próprio negócio, como para aqueles que trabalham em empresas.

\section{REFERÊNCIAS}

BERNARDES, M. E. B; MARTINELLI, D. P. Programa de empreendedorismo em instituições de ensino superior: reflexões a partir de algumas experiências canadenses e americanas. In: ENCONTRO DE ESTUDOS SOBRE EMPREENDEDORISMO E GESTÃO DE PEQUENAS EMPRESAS, 3, 2003, Brasília. Anais... Brasília: UEM/UEL/UnB, 2003, p. 1-13.

CAPES. Fundação Coordenação de Aperfeiçoamento de Pessoal de Nível Superior. Mestrados/doutorados reconhecidos. Disponível em: 
$<$ http://www.capes.gov.br/capes/portal/conteudo/CriacaoReconhecimento_Cursos.pdf $>$. Acesso em: 10 out. 2006.

CO, Mary Jesselyn; MITCHELL, Bruce. Entrepreneurship education in South Africa: a nationwide survey. Education + Trainig, v. 48, n. 5. p. 348-359, 2006.

DELLA GIUSTINA, Ana Paula. O ensino e a produção científica em empreendedorismo nos programas de pós-graduação da região sul do Brasil. 2005. 190f. Dissertação (Mestrado em Administração) - Centro de Ciências Sociais Aplicadas, Universidade Regional de Blumenau, Blumenau, 2005.

DOLABELA, Fernando. Oficina do Empreendedor. São Paulo: Cultura, 1999.

FILION, Louis Jacques. O empreendedorismo como tema de estudos superiores. Disponível em: <http://www.iel.org.br/programa/empreend/discurs4html>. Acesso em: 26 out. 2006.

FLORES, Danusa Cunha. O ensino do empreendedorismo nos cursos de pós-graduação em administração no Brasil. 2006. 132f. Dissertação (Mestrado em Administração) - Centro de Ciências Sociais Aplicadas, Universidade Regional de Blumenau, Blumenau, 2006.

GARAVAN, T.; FLEMING, P.; CINNEIDE, B. Entrepreneurship and business start-ups in Ireland. Dublin: Oak Tree, 1997.

GEM - Global Entrepreneurship Monitor. Relatório 2006. Disponível em: $<$ http://gembrasil.org.br/arquivos//230420073011.ppt $>$. Acesso em 13 jul.2007.

GUIMARÃES, Liliane de Oliveira. Empreendedorismo no currículo dos cursos de graduação e pós-graduação em administração: análise da organização didático-pedagógica destas disciplinas em escolas de negócios norte-americanas. In: ENCONTRO NACIONAL DE PROGRAMAS DE PÓS-GRADUAÇÃO EM ADMINISTRAÇÃO, 26, 2002, Salvador. Anais... Porto Alegre: Pallotti, 2002. 1 CD-ROM.

HEGARTY, Cecilia. It's not an exact sciense: teaching entrepreneurship in Northern Ireland. Education + Training, v. 48, n. 5. p. 322-335, 2006.

HENRIQUE, Daniel Christian; CUNHA, Sieglinde Kindl da. Metodologias, recursos e práticas didático-pedagógicas no ensino de empreendedorismo em cursos de graduação e pós-graduação nacionais e internacionais. In: ENCONTRO NACIONAL DE PROGRAMAS DE PÓSGRADUAÇÃO EM ADMINISTRAÇÃO, 30, 2006, Salvador. Anais... Porto Alegre: Pallotti, 2006. 1 CD-ROM.

JONES-EVANS, D; WILLIAMS, W; DEACON, J. Developing entrepreneurial graduates: an action-learning approach. Education +Training, v. 42, n. 4/5, p. 282-8, 2000. 
KLAPPER, Rita. Government goals and entrepreneurship education - an investigation at a Grande Ecole in France. Education + Training, v. 46, n. 3, p. 127-137, 2004.

LI, J.; ZHANG, Y.; MATLAY, H. Entrepreneurship education in China. Education + Training, v. 45. n. 8/9, p. 495-505, 2003.

MATLAY, H. Entrepreneurship education in UK business schools: conceptual, contextual and policy considerations. Journal of Small Business and Enterprise Development, v. 12, n. 4, p. 627-643, 2005.

MENZIES, T. V. An exploratory study of university entrepreneurship centers in Canada: a first step in model building. Journal of Small Business and Entrepreneurship, n. 15, p. 15-38, 1998.

NORTH, E. A decade of entrepreneurship education in South Africa. South African Journal of Education, v. 22, n. 1, p. 24-27, 2002.

PARDINI, Daniel Jardim; PAIM, Lúcia Regina Corrêa. Empreendedorismo e interdisciplinaridade: uma proposta metodológica no ensino de graduação In: ENCONTRO DE ESTUDOS SOBRE EMPREENDEDORISMO E GESTÃO DE PEQUENAS EMPRESAS, 2, 2001, Londrina. Anais... Londrina: UEL/UEM, 2001, p.227-240.

RAMOS, Simone Cristina; FERREIRA, Jane Mendes. Levantamento das práticas e conteúdos do ensino de empreendedorismo nos cursos de graduação em administração na cidade de Curitiba. In: ENCONTRO DA ASSOCIAÇÃO NACIONAL DE PÓS-GRADUAÇÃO E PESQUISA EM ADMINISTRAÇÃO, 28, 2004, Florianópolis. Anais... Florianópolis: 2004. 1 CD-ROM.

SCHUMPETER, J.A. Capitalismo, socialismo e democracia. Rio de Janeiro: Zahar, 1984. 